\title{
Formulation and evaluation of mefenamic acid sustained release matrix pellets
}

MOHAMED ABBAS IBRAHIM

Department of Pharmaceutics

and Industrial Pharmacy

Faculty of Pharmacy

Al-Azhar University, Assiut, Egypt

\begin{abstract}
The objective of the study was to prepare mefenamic acid (MA) sustained release matrix pellets and investigate the formulation parameters affecting pellet attributes and drug release in vitro. A mixer torque rheometer (MTR) was used to characterize the rheological properties of wet mass used in pellet formulation. Mefenamic acid pellets were prepared by extrusion/spheronization techniques using microcrystalline cellulose (MCC) in combination with lactose as pellet forming agents and water as the binding liquid. Also, the prepared pellets were characterized for their particle size and in vitro drug dissolution. The results revealed that the increase in lactose weight ratio to MCC resulted in a significant reduction of both maximum torque and binder ratios, while the addition of $2 \%$ $(\mathrm{m} / \mathrm{m})$ polyvinyl pyrolidone (PVP) to MCC-lactose influenced only the mean torque rather than the wetting liquid (water). Particle size ranged from 945 to $1089 \mu \mathrm{m}$ and had small span values (0.56-0.67). Furthermore, an inverse relation was observed between the rheological character of pellet wet masses (expressed by peak torque) and in vitro release rate. Increasing MA loading from 2.5 to 5 and $10 \%$ was accompanied by a decrease in dissolution rates. In conclusion, properties of MA matrix pellets could be successfully monitored by controlling the wet mass characteristics by measuring torque.
\end{abstract}

Keywords: mefenamic acid, matrix pellets, mixer torque rheometer, sustained release

Interest in pellets as dosage forms has been increasing continuously. Several therapeutic advantages could be achieved by using pellets as a drug delivery system, over the single-unit regimen, such as less irritation of the gastrointestinal tract and a lowered risk of side effects due to dose dumping (1). Additionally, technological advantages such as

\footnotetext{
* Correspondence; e-mail: abbma71@gmail.com

Current address: Kayyali Chair for Pharmaceutical Industries, Department of Pharmaceuticals, Faculty of Pharmacy, King Saud University, Riyadh 11451, Kingdom of Suadi Arabia.
} 
better flow properties, a less friable dosage form, narrow particle size distribution, ease of coating and uniform packing can be achieved with pellets. Mehta et al. (2) showed that multi-unit dosage forms have gained considerable popularity over conventional single units for controlled release technology. This is due to the rapid dispersion of pellets in the gastrointestinal tract; they maximize drug absorption, reduce peak plasma fluctuations and minimize potential side effects without lowering drug bioavailability. Pellets also reduce variations in gastric emptying rates and overall transit times. Thus, intra and inter-subject variability of plasma profiles, which are common with single-unit regimens, are minimized.

Different authors have utilized pellets and granules as controlled drug delivery system techniques, which do not involve organic solvents or coating, because of stringent global requirements for product safety. As the level of understanding the toxic effects of these solvents is increasing, industrial hygiene rules and FDA regulations are being tightened worldwide, limiting the use of and exposure of workers to these solvents. Furthermore, the attempt to track and optimize the pellet coating process is rather difficult. Also, by developing a matrix sustained release system one can save time and money by omitting the coating operation. Monitoring the coating process by determining the amount of drug or color deposited is tedious, and often leads to large variability (3). Hence, many reports have been published on alternative techniques such as melt granulation (4), melt extrusion (5-6), melt dispersion (7), and melt solidification (8) for controlled drug delivery systems. In addition, several attempts have been made to modify drug release from multi-particulate oral dosage forms by incorporating various hydrophobic materials into the basic formulation for pellets (9). Such systems retard the penetration of aqueous fluids into the formulation and thereby slow the rate of drug release.

It has been shown that the rheological properties of wet masses can be successfully monitored by means of a mixer torque rheometer (10-11). It was shown that the rheological properties of wet mass could affect the release patterns from pellet formulations. Mahrous et al. (12) have observed that an inverse relationship exists between indomethacin release from the pellets and the peak torque values of the used polymer mixture.

Mefenamic acid (MA) [2-(2,3-dimethylphenyl)aminobenzoic acid], an anthranilic acid derivative, is a nonsteroidal anti-inflammatory (NSAI), antipyretic, and analgesic agent that is used for the relief of postoperative and traumatic inflammation and swelling, antiphlogistic and analgesic treatment of rheumatoid arthritis, and antipyretic in acute respiratory tract infection (13).

Mefenamic acid solubility in water is $0.04 \mathrm{mg} \mathrm{mL}^{-1}$ (14). Mefenamic acid is rapidly absorbed after oral administration. Following a single 1 gram oral dose, mean peak plasma levels ranging from 10 to $20 \mathrm{mg} \mathrm{mL}^{-1}$ have been reported. Peak plasma levels are attained in 2 to 4 hours and the elimination half-life approximates 2 hours (15). The short biological half-life of $2 \mathrm{~h}$ following oral dosing necessitates frequent administration of the drug in order to maintain the desired steady state levels (16).

Moreover, dosage regimens involving conventional oral dosage forms require drug administration three or four times daily to maintain adequate therapeutic effectiveness, with inherent problems associated with patient compliance. In addition, conventional dosage forms do not protect patients against morning joint stiffness common in rheumatoid disease states (17). Thus the development and clinical use of sustained or controlled release dosage forms of NSAIDs may have several advantages over the use of conventional formulations, such as reduction of side effects, prolongation of drug action and impro- 
vement of bioavailability and patient compliance (18). Therefore, the formulation of MA as sustained release dosage form matrix pellets could be an alternative approach to overcome the potential problems in the gastrointestinal tract, in addition to minimizing dosing frequency (19-20).

The present study is aimed at formulating sustained release matrix pellets loaded with mefenamic acid using the extrusion/spheronization technique as an alternative to the coating technique. Pellet wet masses were characterized using mixer torque rheometry and also the impact of wet mass peak torque on the in vitro release rate of the drug loaded pellets was assessed.

\section{EXPERIMENTAL}

\section{Materials}

Mefenamic acid was kindly supplied by Al-Jazeera Pharmaceutical Industries (Riyadh, KSA). Lactose monohydrate was purchased from Winlab (UK). Polyvinyl pyrrolidone (PVP K30) was purchased from Fluka (Switzerland). Microcrystalline cellulose, MCC (Avicel ${ }^{\circledR}$ PH101) was purchased from Serva Feinbiochemica (Germany). All other materials and solvents used were of reagent or analytical grade and were used without further purification.

\section{Characterization of pellet wet masses using a mixer torque rheometer}

The mixer torque rheometer used in the present study consists of a 135-mL capacity stainless steel bowl equipped with two mixing blades with rotational speed ranging between 20 and 150 rpm (MTR-3, Caleva, England). Depending on the bulk density, a sample of $15-30 \mathrm{~g}$ of dry powder material is sufficient to cover the mixer blades. The torque is measured directly at the mixer bowl with the help of a torque arm connected from the main body of the mixer to a calibrated load transducer. The following equipment settings were used for all the studies: mixer speed, $50 \mathrm{rpm}$. Data acquisition and analyses were carried out with a personal computer using the data acquisition system and software package supplied by the equipment manufacturer.

Powders were mixed in a turbula mixer (type S27, Erweka, Apparatebau, Germany) and a 15-gram sample of this dry blend was utilized in the wet massing studies. Two milliliters of granulating fluid were added in multiple additions over 15 wet massing intervals. Each wet massing interval consisted of a one minute mixing period and a 20-second torque data logging (collection) period with the MTR operating at $50 \mathrm{rpm}$. Mean torque was monitored during the granulation process.

\section{Manufacture of pellets}

Water was used as a granulating liquid in the manufacture of MA-loaded pellets. The water volume required for wet massing was selected according to the highest torque value measured by the rheometer. Compositions of different pellet formulations are shown in Table I. MA and pellet excipients were mixed in a turbula mixer at certain weights and the powder mixture was wetted with water. Next, the resulting wet mass was ex- 
Table I. Composition of different pellet formulations loaded with mefenamic acid

\begin{tabular}{lcccccccccc}
\hline \multirow{2}{*}{$\begin{array}{l}\text { Ingredient } \\
\text { \%) }\end{array}$} & \multicolumn{10}{c}{ Formula } \\
\cline { 2 - 11 } & M1 & M2 & M3 & M4 & M5 & M6 & M7 & M8 & M9 & M10 \\
\hline MCC & 93 & 83 & 73 & 43 & 95 & 85 & 75 & 45 & 47.5 & 40 \\
Lactose & - & 10 & 20 & 50 & - & 10 & 20 & 50 & 50 & 50 \\
PVP K 30 & 2 & 2 & 2 & 2 & - & - & - & - & - & - \\
MA & 5 & 5 & 5 & 5 & 5 & 5 & 5 & 5 & 2.5 & 10 \\
Water & & & & \multicolumn{7}{c}{ q.s. } \\
\hline
\end{tabular}

truded at a speed of $90 \mathrm{rpm}$ with a screen pore size of $1 \mathrm{~mm}$ (Mini Screw Extruder, Model MSE1014, Caleva, England). Spheronization was performed in a spheronizer (Model 120, Caleva, England) with a rotating plate of regular cross-hatch geometry, at a speed of $700 \mathrm{rpm}$, for 5 minutes. Pellets were then dried on a tray in a hot oven at $50-60{ }^{\circ} \mathrm{C}$ for 6 hours.

\section{Drug content}

Mefenamic acid (MA) content of the manufactured pellets was determined spectrophotometrically at $285 \mathrm{~nm}$ in triplicate. Pellets were crushed in a porcelain mortar and about $25 \mathrm{mg}$ of the crushed pellets was dispersed in $250 \mathrm{~mL}$ of phosphate buffer (pH 6.8) under sonication for 5 minutes. The supernatant was filtered through a cellulose nitrate filter with pores of $0.2 \mu \mathrm{m}$ in diameter (Sartorius, Germany) and measured spectrophotometrically (UV-2800 spectrophotometer, Labomed Inc., USA); MA content was then calculated using a pre-constructed calibration curve.

\section{Morphological analysis}

Morphological characteristics of particles were observed by scanning electron microscopy (SEM). The samples were sputter-coated with a thin gold palladium layer under an argon atmosphere using a gold sputter module in a high-vacuum evaporator. Coated samples were then scanned and photomicrographs were taken with an SEM (Jeol JSM-1600, Japan).

\section{Particle size analysis}

The size distribution of the manufactured pellets was investigated using laser light diffraction (Mastersizer Scirocco 2000, Malvern Instruments, UK). For a typical experiment, about $300 \mathrm{mg}$ of pellets were fed in the sample micro feeder. All samples were analyzed 5 times and average results were taken. The pellets of 10th $(d(0.1)), 50$ th $(d(0.5))$ and 90th $(d(0.9))$ percentage were used to characterize the pellet size distribution. The approximate mean diameter was taken as the average of $d(0.1), d(0.5)$, and $d(0.9)$ values. 
The span value was employed to characterize the pellet size distribution, since a small span value indicates a narrow particle size distribution. It was calculated from the following formula (21):

$$
\text { Span }=\frac{d(0.9)-d(0.1)}{d(0.5)}
$$

\section{In vitro dissolution studies}

Dissolution measurements were performed using an automated dissolution tester (LOGAN Instrument Corp., USA) coupled to an automated sample collector (SP-100 peristaltic pump, USA). The USP dissolution basket method (apparatus 1) was used. MA loaded pellets equivalent to $25 \mathrm{mg}$ MA were added to $500 \mathrm{~mL}$ of dissolution medium (phosphate buffer, $\mathrm{pH} 7.4$ ). The temperature was maintained at $37 \pm 0.5^{\circ} \mathrm{C}$. An accurately weighed amount of the prepared pellets was added to each flask. For each sample formula, drug dissolution was run in triplicate and absorbance was recorded automatically at $285 \mathrm{~nm}$ up to $8 \mathrm{~h}$. The percentage of drug dissolved was determined as a function of time.

\section{Statistical analysis}

The results were analyzed using the software GraphPad Prism5 (GraphPad Software, La Jolla, USA) applying one-way ANOVA. Differences between formulations were considered to be significant at $p \leq 0.05$.

\section{RESULTS AND DISCUSSION}

\section{Wet massing studies}

Wet massing experiments were performed for MCC-lactose-PVP systems in order to establish the water/powder ratio needed to reach a maximum torque response. For the MCC-lactose systems, Fig. 1, different liquid saturation phases (pendular, funicular and capillary) were passed through, with the maximum torque occurring at the capillary state. MCC system exhibited a typical progression of liquid saturation phases. The mean torque value was found to increase with an increase in wet massing liquid (water). However, different profiles were detected regarding MCC-lactose systems in which the increase of lactose weight resulted in a significant reduction of the area of MTR curve, i.e., progression of liquid saturation phases occurred at lower water/powder ratio. In addition, reductions of peak torque water/powder ratios $\left(\mathrm{mL} \mathrm{g}^{-1}\right)$ and peak torque magnitudes were recorded, with the lowest value $(0.156 \mathrm{~N} \mathrm{~m})$ at the $50 \%(\mathrm{~m} / \mathrm{m})$ lactose level, Fig. 1 . Rheological behaviors of MCC-lactose systems containing $2 \%(\mathrm{~m} / \mathrm{m})$ PVP (Fig. 2) are quite different when compared to MCC-lactose systems. Addition of $2 \%(\mathrm{~m} / \mathrm{m})$ PVP to this powder mixture influenced only the maximum torque rather than water volume at maximum torque. The degree of liquid spreading and wetting as well as the substrate-granulating 


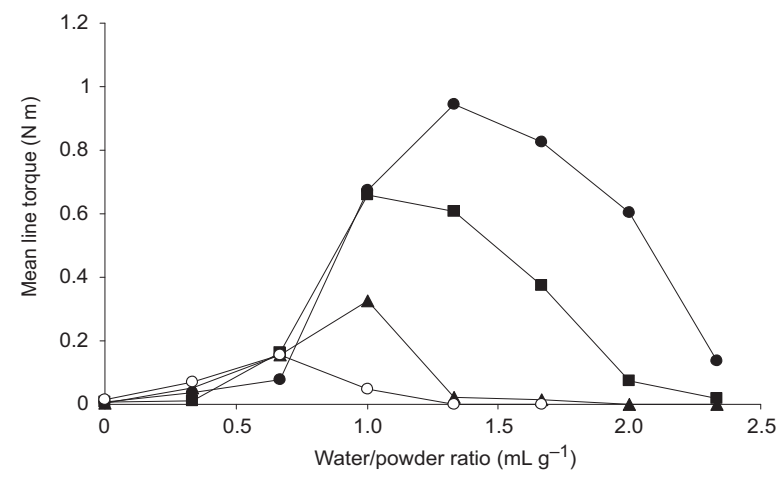

Fig. 1. Effect of different concentrations of lactose on mean torque for MCC PH101: $0(\bullet), 10 \%(\bullet)$, $20 \%(\mathbf{\Lambda})$ and $50 \%(0)$.

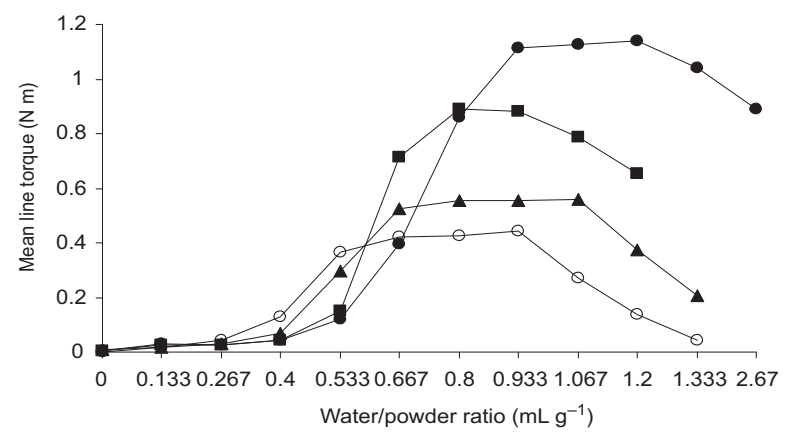

Fig. 2. Effect of different concentrations of lactose on mean torque for Avicel PH101 containing $2 \%$ PVP: $0(\bullet), 10 \%(\mathbf{\bullet}), 20 \%(\mathbf{\Delta})$ and $50 \%(0)$.

liquid interaction will determine the relative positions of peak values of the mean line torque (22). In addition, the pendular and funicular states are characterized by a progressively increasing network of liquid bridges. Both of these stages will cause an increase in cohesiveness of the powder mass and hence an increased torque on the mixer (23-24). The capillary state which is reached when all air spaces in the granular material are filled with liquid occurs at the maximum on the curve. With further addition of liquid, the torque decreases as a slurry of particles dispersed in liquid is formed.

\section{Pellets sizes and shapes}

The volume weighted mean particle size and the $d(0.1), d(0.5)$ and $d(0.9)$ values of different pellet formulae loaded with MA, as determined by laser diffractometry, are listed in Table II. In general, the volume weighted mean of the manufactured pellets was found to be in a range from 945 to $1089 \mu \mathrm{m}$. In addition, the particle size distribution of MA sustained release matrix pellets was characterized by small span values. Calculated span values for all pellet formulations were found to be $0.56-0.67$, indicating a narrow particle size distribution (25). 
Table II. Volume weighted mean particle size and the $\mathrm{d}(0.1), \mathrm{d}(0.5), \mathrm{d}(0.9)$ and span values of different pellet formulae loaded with $M A(5 \%(\mathrm{~m} / \mathrm{m})$ as determined by laser diffractometry)

\begin{tabular}{cccccc}
\hline Pellet formulae & Mean $d(\mu \mathrm{m})$ & $d(0.1)(\mu \mathrm{m})$ & $d(0.5)(\mu \mathrm{m})$ & $d(0.9)(\mu \mathrm{m})$ & Span value \\
\hline M1 & 1027.11 & 760.59 & 1065.27 & 1471.1 & 0.67 \\
M2 & 1016.86 & 762.99 & 1049.44 & 1415.72 & 0.62 \\
M3 & 944.95 & 710.58 & 973.86 & 1337.41 & 0.64 \\
M4 & 1080.23 & 825.78 & 1113.51 & 1479.38 & 0.59 \\
M5 & 1045.12 & 690.10 & 984.19 & 1398.10 & 0.72 \\
M6 & 1005.18 & 675.14 & 915.48 & 1218.4 & 0.59 \\
M7 & 993.10 & 750.23 & 1020.39 & 1388.95 & 0.63 \\
M8 & 999.83 & 737.30 & 1041.90 & 1435.65 & 0.67 \\
M9 & 1034.89 & 791.22 & 1062.04 & 1412.97 & 0.59 \\
M10 & 1089.15 & 825.14 & 1087.45 & 1428.10 & 0.56 \\
\hline
\end{tabular}

Scanning electron micrographs of some sustained release MA matrix pellet formulations (M4, M8 and M9) are displayed in Figure 3. The prepared pellet formulas F8 and F9 appear almost rounded and intact in shape, while M4 pellets are not completely spherical. This might be due to the higher mean torque value of the wet mass of formula M4 $(0.445 \mathrm{~N} \mathrm{~m})$ compared to the lower torque value of formula M8 $(0.156 \mathrm{~N} \mathrm{~m})$. These

a)
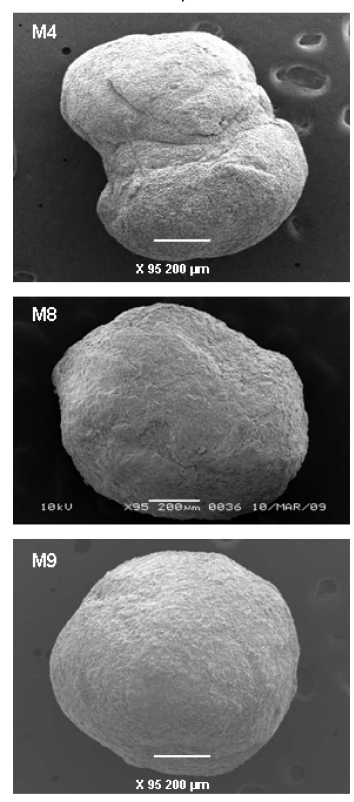

b)
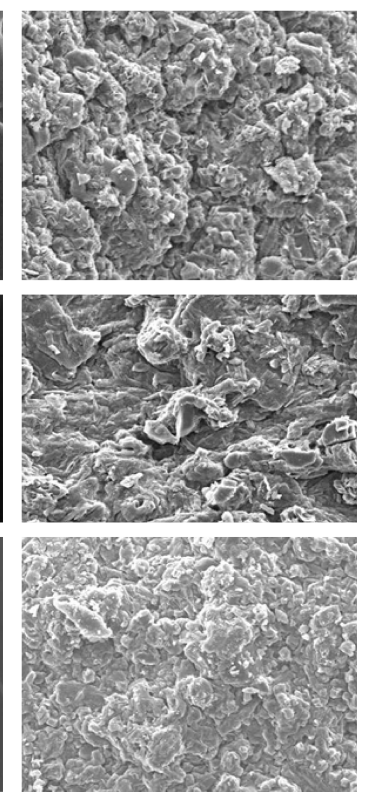

Fig. 3. Scanning electron micrographs of: a) pellets, b) pellet surfaces. 
results are in accord with the data obtained by Mahrous et al. (12), who showed that the more hydrophilic polymer (PEG 4000), when mixed with MCC, produced a wet mass having the lowest mean torque value compared to that recorded with the same weight ratio of PVP and HPMC. This in turn reflects on the easy extrusion of the PEG wet mass, resulting in pellets with smoother surfaces. In addition, Law and Deasy (26) reported that the use of hydrophilic polymers with MCC favored more spherical and smooth pellets.

\section{In vitro release studies}

Pellet drug content was calculated before in vitro dissolution studies. The obtained data showed that MA content ranged from 95 to $105 \%$ of the theoretical content, indicating homogenous drug distribution in the prepared pellets.

Apart from influencing the yield and sphericity of the product, addition of excipients such as CMC and lactose could also affect drug release. Mixes of various hydrophilic
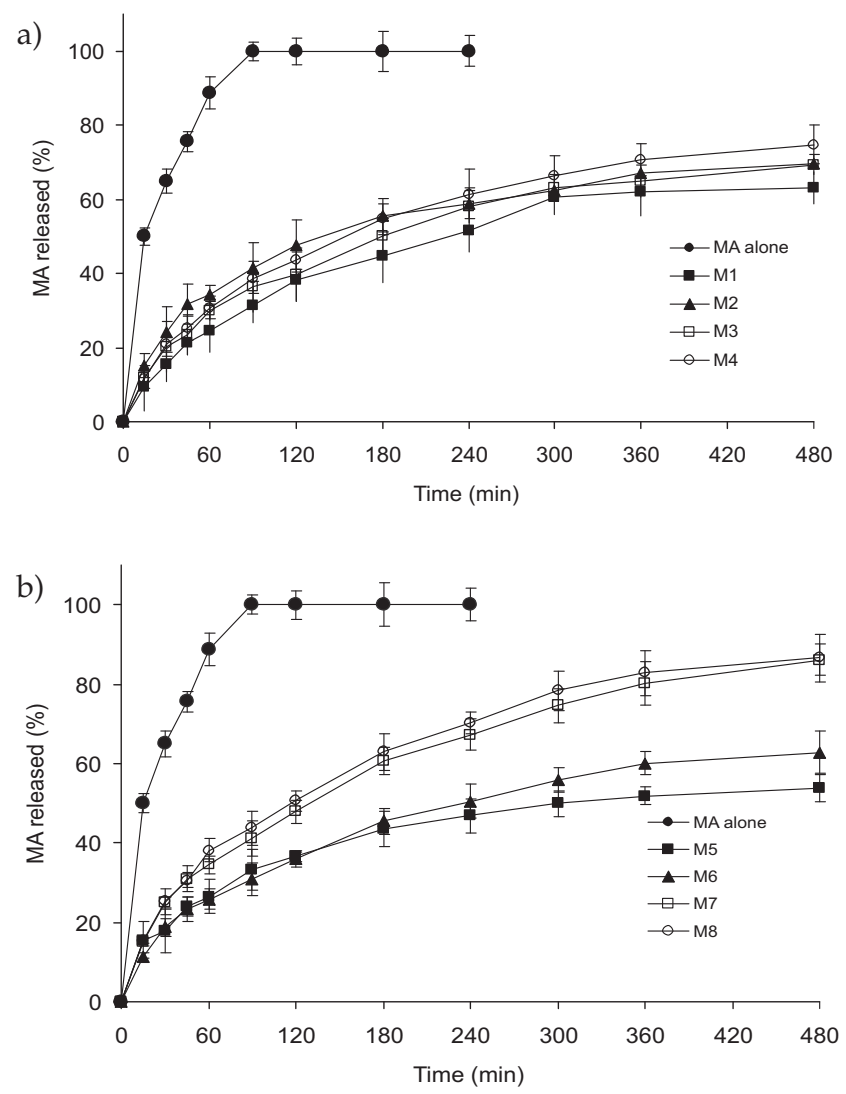

Fig. 4. In vitro release profiles of mefenamic acid from pellet formulations: a) M1-M4, b) M5-M8 $($ mean $\pm \mathrm{SD})$. 
polymers with MCC (1:19) were reported previously by Law and Deasy (26) to aid extrusion-spheronization and, at the same time, to enhance the dissolution of indomethacin.

The in vitro release data of MA from pellet formulations are displayed in Fig. 4. It can be seen that untreated MA was completely released in less than 90 minutes. Incorporation of the drug in pellet formulations containing PVP (M1-M4) resulted in slowing its release rate in dependence on the weight of the hydrophilic additive (lactose) in the formula. Increasing lactose weight was accompanied by an enhancement of the drug release rate. For example, about $75 \%$ of incorporated MA was released from the pellet formula containing $50 \%$ lactose (M4), while only $63 \%$ was releaseed from the pellet formula containing only $10 \%$ lactose (M1). Lactose enhances the drug release rate by forming pores and it also promotes water penetration into the formulation core. In addition, increasing the lactose concentration caused a pronounced lowering of the mean torque of pellet wet mass before extrusion/spheronization procedures. The in vitro release of MA from pellet formulations that do not contain PVP (M5-M8) is illustrated in Fig. 4b. The results revealed that MA exhibited a faster release pattern from pellet formulas that contain MCC and lactose compared to the pellets made by blending these excipients with PVP. Similarly, a pronounced enhancement of MA release from formulae M5 to M8 was a result of increased lactose weight, especially for formulae M7 and M8 containing 20 and $50 \%$ lactose, respectively. The dependence of MA release rate from these pellet formulations could be explained on the basis of the inverse relationship between the release rate (represented by \% MA release after $480 \mathrm{~min}$ ) and the peak torque values of the pellet wet mass, as shown in Fig. 5. Ibrahim et al. (27) found an inverse relationship between
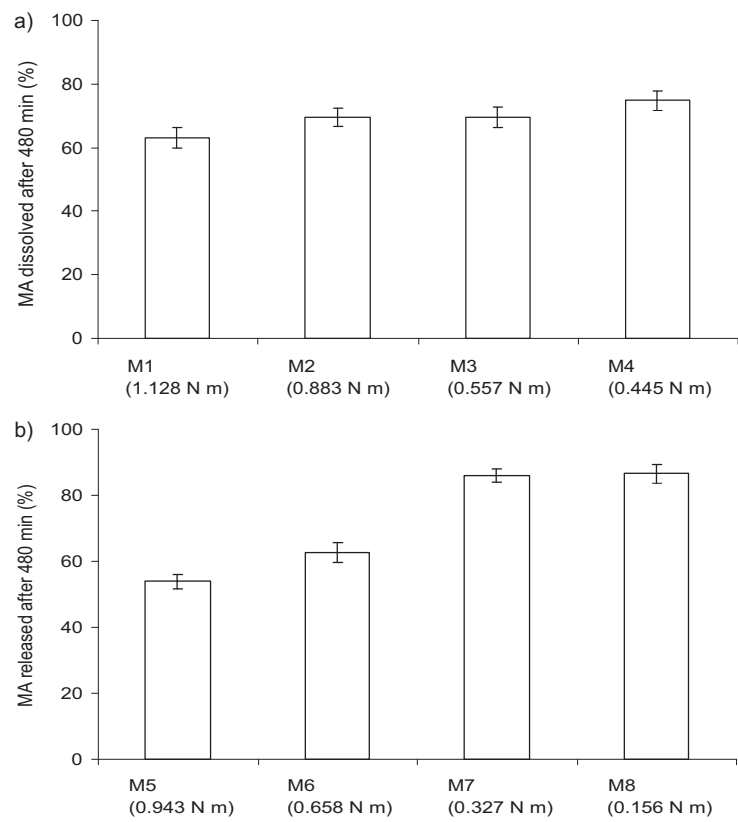

Fig. 5. Correlation between the pellet wet mass peak torque and the percent of mefenamic acid released after 480 minutes from a) M1-M4 formulae and b) M5-M8 formulae (mean \pm SD). 
indomethacin release from its loaded pellets and the peak torque values of the polymer mixed with co-solvents.

The effect of pellet wet masses peak torque on the calculated Higuchi diffusion slope $\left(\%\right.$ MA released min $\left.^{-0.5}\right)$ is illustrated in Fig. 6. Inverse proportionality between the peak torque and MA diffusion rate was pronounced in the systems containing MCC and lactose only (formulas M5-M8), Fig. 6b. However, in pellet formulations containing PVP (formulas M1-M4), a slight retarding action of wet mass peak torque on the Higuchi diffusion slope was observed, Fig. 6 a.

The effect of MA loading on the in vitro drug release from a selected pellet formula (M8) is shown in Fig. 7. It is clearly evident that increasing MA concentration in the pellet formula resulted in retardation of its release rate. For example, MA showed complete release from the pellet formula containing $2.5 \%$ drug (M9), while only $73 \%$ was released from the formula containing $10 \%$ MA (M10). This might be explained by the assumption that increasing the concentration of the poorly soluble drug will decrease the content of the hydrophilic excipient lactose. Similar findings were observed by Zhou et al. (28), who showed that the decrease of ibuprofen release from matrix pellets at higher drug concentrations was due to a decrease in starch content. This results in a reduction of hydrophilic pathways for water molecules to access drug crystals inside the pellet. The same phenomenon was also observed by Adeyeye and Price (29).
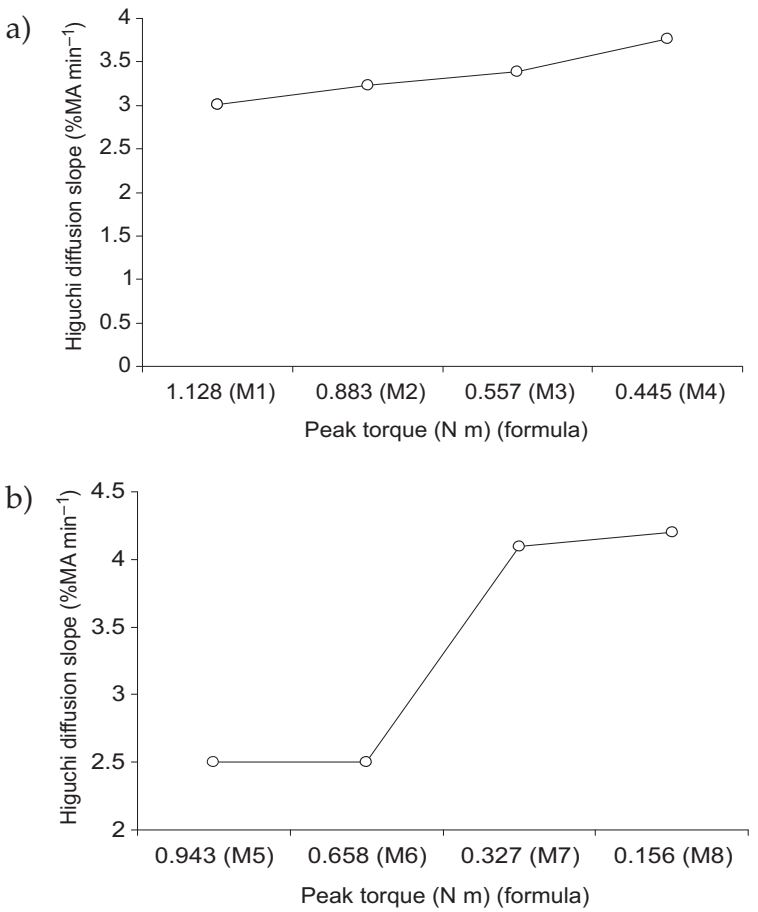

Fig. 6. Correlation between the pellet wet mass peak torque and the Higuchi diffusion slope calculated for: a) M1-M4 formulae, b) M5-M8 formulae. 


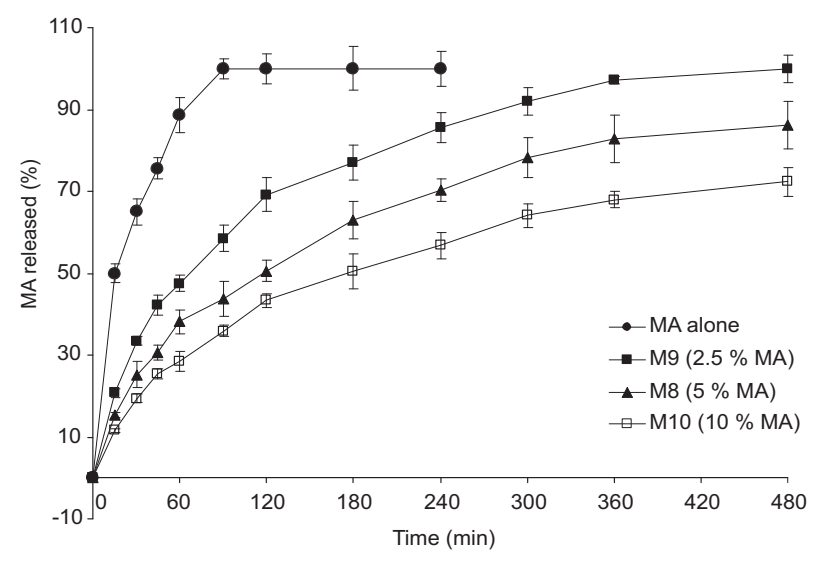

Fig. 7. Effect of different mefenamic acid concentrations on in vitro release profiles from pellet formulation M8 (mean $\pm \mathrm{SD})$.

\section{Kinetic modeling of in vitro release of MA from matrix pellets}

The in vitro release data of MA from different sustained release matrix pellets were fitted using the zero order, first order and Higuchi diffusion models as well as the Korsmeyer-Peppas equation to determine the model that best describes drug release from pellet formulations. Preference of the release mechanism is based on the value of the correlation coefficient. The data revealed a good fit to the Korsmeyer-Peppas equation, indi-

Table III. Kinetic modeling of MA release from different sustained release matrix pellet formulations

\begin{tabular}{cccccc}
\hline \multirow{2}{*}{ Formula } & \multicolumn{5}{c}{$R$} \\
\cline { 2 - 6 } & $\begin{array}{c}\text { Zero order } \\
\text { model }\end{array}$ & $\begin{array}{c}\text { First order } \\
\text { model }\end{array}$ & $\begin{array}{c}\text { Higuchi diffusion } \\
\text { model }\end{array}$ & $\begin{array}{c}\text { Peppas } \\
\text { model }\end{array}$ & $n$ \\
\hline M1 & 0.930 & 0.960 & 0.990 & 0.990 & 0.56 \\
M2 & 0.888 & 0.949 & 0.979 & 0.983 & 0.43 \\
M3 & 0.926 & 0.971 & 0.991 & 0.991 & 0.51 \\
M4 & 0.928 & 0.978 & 0.992 & 0.989 & 0.53 \\
M5 & 0.887 & 0.928 & 0.978 & 0.989 & 0.4 \\
M6 & 0.887 & 0.928 & 0.978 & 0.989 & 0.39 \\
M7 & 0.939 & 0.995 & 0.996 & 0.995 & 0.49 \\
M8 & 0.929 & 0.990 & 0.993 & 0.993 & 0.50 \\
M9 (M8 + 2.5 \% MA) & 0.920 & 0.988 & 0.991 & 0.990 & 0.47 \\
M10 (M8 + 10 \% MA) & 0.934 & 0.980 & 0.994 & 0.992 & 0.52 \\
\hline
\end{tabular}

$R$ - correlation coefficient; $n$ - the release exponent obtained from Korsmeyer-Peppas equation 
cating combined effects of diffusion and erosion mechanisms for drug release (30). In addition, the release exponent $(n)$ was calculated from the Korsmeyer equation (31):

$$
\frac{M_{t}}{M_{\infty}}=k t^{n}
$$

The data displayed in Table III showed that the calculated values of $n$ were lower and higher than 0.45 , but all were less than 1, indicating also non-Fickian or anomalous drug release or the so called coupled diffusion/polymer relaxation. Moreover, slight swelling and erosion of the pellet matrix were observed for the manufactured matrix pellets, and the pellets did not disintegrate in the dissolution medium even after 8 hours. It has been concluded by several authors that when liquid diffusion rate and polymer relaxation rate (erosion) are of equal magnitude, anomalous or non-Fickian diffusion is observed $(30,32)$.

\section{CONCLUSIONS}

In conclusion, the properties of MA matrix pellets could be successfully correlated with the wet mass characteristic using mixer rheometry. This will help obtain a controlled release dosage form capable of lowering the risk of side effects and improving patient convenience as an advantage of pellets as a drug delivery system.

Acknowledgment. - The authors extend their appreciation to the Deanship of Scientific Research at King Saud University for funding the work through the research group project No. RGP-VPP-139.

\section{REFERENCES}

1. H. Bechgaard and G. H. Nielsen, Controlled-release multiple-units and single-unit doses. A literature review, Drug Dev. Ind. Pharm. 4 (1978) 53-67; DOI: 10.3109/03639047809055639.

2. K. A. Mehta, M. S. Kislalioglu, W. Phuapradit, A. W. Malick and N. H. Shah, Release performance of a poorly soluble drug from a novel, Eudragit ${ }^{\circledR}$-based multi-unit erosion matrix, Int. J. Pharm. 213 (2001) 7-12; DOI: 10.1016/S0378-5173 (00)00594-9.

3. P. W. Heng, 15th International Symposium on Microencapsulation, Parma (Italy), September 18-21, 2005.

4. T. Schaefer, P. Holm and H. G. Kristensen, Melt granulation in a laboratory scale high shear mixer, Drug Dev. Ind. Pharm. 19 (1990) 1249-1277; DOI: 10.3109/03639049009115960.

5. O. L. Sprockel, M. Sen, P. Shivanand and W. Prapaitrakul, A melt extrusion process for manufacturing matrix drug delivery systems, Int. J. Pharm. 155 (1997) 191-199; DOI: 10.1016/S0378-5173(97)00165-8.

6. C. De Brabander, C. Vervaet and J. P. Remon, Development and evaluation of sustained release mini-matrices prepared via hot melt extrusion, J. Control. Release 89 (2003) 235-247; DOI: 10.1016/ S0168-3659(03)00075-0.

7. N. Follonier, E. Doelker and E. T. Cole, Evaluation of hot melt extrusion as a new technique for the development of polymer base pellets for sustained release capsules containing high loadings of freely soluble drugs, Drug Dev. Ind. Pharm. 20 (1994) 1323-1339; DOI: 10.3109/03639049409038373. 
8. F. Siepmann, S. Muschert, M. P. Flament, P. Leterme, A. Gayot and J. Siepmann, Controlled drug release from Gelucire based matrix pellets: Experiment and theory, Int. J. Pharm. 317 (2006) 136-143; DOI: 10.1016/j.ijpharm.2006.03.006.

9. E. S. Ghali, G. H. Klinger and J. B. Schwartz, Thermal treatment of beads with wax for controlled release, Drug Dev. Ind. Pharm. 15 (1989) 1311-328; DOI: 10.3109/03639048909062747.

10. R. Chatlapalli and B. D. Rohera, Study of effect of excipient source variation on rheological behavior of diltiazem HCl-HPMC wet masses using a mixer torque rheometer, Int. J. Pharm. 238 (2002) 139-151; DOI: 10.1016/S0378-5173(02)00065-0.

11. J. L. P. Soh, C. W. Liew and P. W. S. Heng, Torque rheological parameters to predict pellet quality in extrusion-spheronization, Int. J. Pharm. 315 (2006) 99-109; DOI: 10.1016/j.ijpharm.2006.02.023.

12. G. M. Mahrous, M. A. Ibarhim, M. El-Badry and F. K. Al-Anazi, Indomethacin sustained release pellets prepared by extrusion/spheronization, J. Drug Deliv. Sci. Technol. 20 (2010) 119-125.

13. L. Fang, S. Numajiri, D. Kobayashi, H. Ueda, K. Nakayama, H. Miyamae and Y. Morimoto, Physicochemical and crystallographic characterization of mefenamic acid complexes with alkanolamines, J. Pharm. Sci. 93 (2004) 144-154; DOI: 10.1002/jps.10468.

14. D. Shinkuma, T. Hamaguchi, Y. Yamanaka and N. Mizuno, Correlation between dissolution rate and bioavailability of different commercial mefenamic acid capsules, Int. J. Pharm. 21 (1984) 187-200; DOI: org/10.1016/0378-5173(84)90093-0.

15. C. V. Winder, D. H. Kaump, A. J. Glazko and E. L. Holmes, Pharmacology of the Fenamates - Experimental Observations on Flufenamic, Mefenamic, and Meclofenamic Acids, in Supplement to Annals of Physical Medicine - Fenamates in Medicine, Symposium (Ed. P. H. Kendall), Bailliere, Tindall and Cassell, London 1966.

16. J. E. F. Reynolds, Martindale: The Extra Pharmacopoeia, 31rd ed., The Pharmaceutical Press, London 1998, pp. 58-59.

17. A. Avgerinos and S. Malamataris, Bioavailability of controlled release indomethacin microspheres and pellets, Int. J. Pharm. 63 (1990) 77-80; DOI: org/10.1016/0378-5173(90)90104-C.

18. J. S. Rowe and J. E. Carless, Comparison of the in vitro dissolution behaviour of various indomethacin formulations with their in vivo bioavailability, J. Pharm. Pharmacol. 33 (1981) 561-464; DOI: $10.1111 / j .2042-7158.1981 . t b 13866 . x$.

19. S. Y. Khan and M. Akhter, Glyceride derivatives as potential prodrugs: synthesis, biological activity and kinetic studies of glyceride derivatives of mefenamic acid, Pharmazie 60 (2005) 110-114.

20. F. Sevgi, B. Kaynarsoy, M. Ozyazici, Ç. Pekcetin and D. Özyurt, A comparative histological study of alginate beads as a promising controlled release delivery for mefenamic acid, Pharm. Dev. Technol. 13 (2008) 387-392; DOI: 10.1080/10837450802244876.

21. P. C. Chen, Y. J. Park, L. C. Chang, D. S. Kohane, R. R. Bartlett, R. Langer and V. C. Yang, Injectable microparticle-gel system for prolonged and localized lidocaine release. I. In vitro characterization, J. Biomed. Mater. Res. A. 70 (2004) 412-419; DOI: 10.1002/jbm.a.30086.

22. M. D. Parker, R. C. Rowe and N. G. Upjohn, Mixer torque rheometry: A method for quantifying the consistency of wet granulations, Pharm. Tech. Int. 2 (1990) 50-64.

23. M. D. Parker, P. York and R. C. Rowe, Binder-substrate interactions in wet granulation. 1: The effect of binder characteristics, Int. J. Pharm. 64 (1990) 207-216.

24. P. Luukkonen, T. Schæfer, L. Hellén, A. M. Juppo and J. Yliruusi, Rheological characterization of microcrystalline cellulose and silicified microcrystalline cellulose wet masses using a mixer torque rheometer, Int. J. Pharm. 188 (1999) 181-192; DOI: 10.1016/S0928-0987(00)00197-4.

25. V. R. Sinha, A. Aggarwal, S. Srivastava and H. Goel, Influence of operational variables in multi-particulate delayed release systems for colon-targeted drug delivery of celecoxib using extrusion spheronization, Asian J. Pharm. 4 (2010) 102-109; DOI: 10.4103/0973-8398.68460.

26. M. F. L. Law and P. B. Deasy, Use of canonical and other analyses for the optimization of an extrusion-spheronization process for indomethacin, Int. J. Pharm. 146 (1997) 1-9; DOI: 10.1016/ S0378-5173(96)04741-2. 
27. M. A. Ibrahim, G. M. Mahrous, M. El-Badry and F. K. Al-Anazi, Indomethacin-loaded pellets prepared by extrusion/spheronization: Effect of cosolvents, Farmacia 59 (2011) 483-499.

28. F. Zhou, C. Vervaet and J. P. Remon, Matrix pellets based on the combination of waxes, starches and maltodextrins, Int. J. Pharm. 133 (1996) 155-160; DOI: 10.1016/0378-5173(95)04431-0.

29. C. M. Adeyeye and J. C. Price, Development and evaluation of sustained-release ibuprofen-wax microspheres. II. In vitro dissolution studies, Pharm. Res. 11 (1994) 575-579; DOI: 10.1023/A: 1018931002991.

30. R. W. Korsmeyer and N. A. Peppas, Macromolecular and Modeling Aspects of Swelling-controlled Systems, in Controlled Release Delivery Systems (Eds. T. J. Roseman and S. Z. Mansdorf), Dekker, New York 1983, pp. 77-101.

31. R. W. Korsmeyer, R. Gurny, E. Docler, P. Buri and N. A. Peppas, Mechanism of solute release from porous hydrophilic polymers, Int. J. Pharm. 15 (1983) 25-35; DOI: 10.1016/0378-5173(83)90064-9.

32. P. L. Ritger and N. A. Peppas, A simple equation for description of solute release ii. Fickian and anomalous release from swellable devices, J. Control. Release, 5 (1987) 37-42; DOI: 10.1016/0168$-3659(87) 90035-6$. 